\title{
Talep Birleştiricilerin Rol Aldığı Elektrik Piyasa Mekanizmaları ve Türkiye'deki Mevcut Durum Analizi ${ }^{1}$
}

\author{
Osman Bülent TÖR (https://orcid.org/0000-0002-7634-2475), EPRA Engineering, Procurement, Research and \\ Analysis, Turkey; e-mail: osman.tor@epra.com.tr
}

Hüseyin OĞUZ (https://orcid.org/0000-0001-8128-7215), EPRA Engineering, Procurement, Research and Analysis, Turkey; e-mail: huseyin.oguz@epra.com.tr

Sabri Murat KISAKÜREK (https://orcid.org/0000-0002-8114-0341), Department of Informatics, Kahramanmaraş Istiklal University, Turkey; e-mail: murat.kisakurek@istiklal.edu.tr

Elif Naz KURŞUNCU (https://orcid.org/0000-0003-1290-9273), AKEDAŞ Elektrik Dağıtım A.Ş., Turkey; e-mail: elifnaz.kursuncu@akedasdagitim.com.tr

Ali Osman KÖKSAL (https://orcid.org/0000-0002-8589-2399), AKEDAŞ Elektrik Dağltım A.Ş., Turkey; e-mail: aliosman.koksal@akedasdagitim.com.tr

\section{Electricity Market Mechanisms for Aggregators and Current State Analysis in Turkey ${ }^{2}$}

\begin{abstract}
The share of renewable energy sources (RES) in electric power systems has been increasing tremendously given the reduction in their capital costs and incentives for renewable generation. This necessitates an increase in flexibility of power systems, which could be described as the capability of power grids in responding to a supply-demand mismatch. Aggregators provide flexible services in distribution grids. This study focuses on electric market mechanisms, which the aggregators provide services, and the players' roles in such market mechanisms. In this regard, the most prevailing international market mechanisms and general trends are addressed, along with the required coordination between transmission system operators (TSO) and distribution system operators (DSO)

I Bu çalışma "Multi-Layer Aggregator Solutions to Facilitate Optimum Demand Response and Grid Flexibility" (SMART-MLA) adlı projesinde elde edilen bazı sonuçlart içermektedir. "ERA-NET Smart Energy Systems SG+ 2017” Programı altında projeyi desekleyen kuruluşlar: TÜBİTAK-Türkiye, Swedish Energy Agency (SWEA)İsveç, Energy Technology Development and Demonstration Program (EUDP)-Danimarka, Executive Agency for Higher Education, Research, Development and Innovation Funding (UEFISCDI)-Romanya ve Research Council of Norway (RCN)-Norveç. TÜBITAK TEYDEB) destek programı: 1509-Uluslararasi Sanayi Ar-Ge Projeleri. Proje No: 9180003. Çalışma ayrıca KOSGEB ARGE ve INOVASYON Programı tarafindan da destek alan "Şebeke Esneklik Çözümlerinin Elektrik Piyasa ve Şebeke Simülasyonları ile Analiz Edilebilmesine Yönelik Modelleme, Simülasyon ve Optimizasyon Yöntemleri Araştırma ve Geliştirme Projesi” nden elde edilen sonuçların bir kısmını da içermektedir.

2 This study is supported in part by the Scientific Results of the Transnational Project "Multi-Layer Aggregator Solutions to Facilitate Optimum Demand Response and Grid Flexibility” (SMART-MLA) under Project 89029, in part by the TÜBİTAK, Turkey, Swedish Energy Agency (SWEA), Sweden, Energy Technology Development and Demonstration Program (EUDP), Denmark, Executive Agency for Higher Education, Research, Development and Innovation Funding (UEFISCDI), Romania, and Research Council of Norway (RCN), Norway, under ERA-Net Smart Energy Systems, through the SG+ 2017 Program, in part by the "TÜBITAK Technology and Innovation Funding Program Directorate (TEYDEB) 1509-UluslararasiSanayi Ar-Ge Projeleri" Program under Grant 9180003, and in part by the "Small and Medium Industry Development Organization (KOSGEB) Research and Development and Innovation Program" with title of "Şebeke Esneklik Çözümlerinin Elektrik Piyasa ve Şebeke Simülasyonlart ile Analiz Edilebilmesine Yönelik Modelleme, Simülasyon ve Optimizasyon Yöntemleri Araştırma ve Geliştirme Projesi”.
\end{abstract}


in such mechanisms. Computer simulation analysis is performed to illustrate the importance of this coordination, particularly after photovoltaic (PV) solar generation in distribution grids. Finally, relevant legislations and current implementations in Turkey are investigated along with recommendations.

\section{Keywords}

JEL Classification Codes : $\quad$ N70, P48, Q48.
Aggregators, Ancillary Services, Electricity Markets, Renewable

Energy, Distribution System Operator, Transmission System

Operator, Legislation, Grid Flexibility.

\section{$\ddot{\mathrm{O} z}$}

Son y1llarda yenilenebilir enerji kaynaklarına (YEK) dayalı elektrik üretim tesislerinin maliyetlerinin azalması ve yenilenebilir enerji üretimini teşvik eden mekanizmalar ile birlikte, yenilenebilir enerjinin elektrik şebekelerindeki payı hızla artmaya başlamıştır. YEK'lerin miktarının artması, elektrik sistemlerinin talep ve arzdaki değişime yanıt verme kabiliyeti olarak tanımlanan şebeke işletme esnekliğine olan ihtiyacı arttırmaktadır. Elektrik dağıtım şebekesine bağlı üretim ve tüketim noktalarında şebeke esneklik hizmeti, talep birleştiriciler tarafından sağlanmaktadır. Bu çalışmada, talep birleştiricilerin hizmet verdiği elektrik piyasa mekanizmalarına ve bu piyasalardaki oyuncuların rollerine odaklanılmıştır. Bu kapsamda uluslararası öne çıkan mekanizmalar ve genel trend açıklanmış ve farklı mekanizmalarda iletim sistemi operatörleri (ISO) ve dağıtım sistemi operatörleri (DSO) arasında gerekli olan koordinasyon ihtiyacı açıklanmıştır. Son yıllarda dağıtım şebekesinde sayıları önemli oranda artış gösteren ve artmaya devam eden fotovoltaik (PV) güneş santralleri sonrası önemi daha da artmış olan bu koordinasyon ihtiyacı bilgisayar simülasyon analizleri ile vurgulanmıştır. Son olarak, talep tarafı katılımında Türkiye'deki mevzuat ve uygulamalar irdelenmiş ve öneriler sunulmuştur.

Anahtar Sözcükler $\quad$ : Talep Birleştiriciler, Yan Hizmetler, Elektrik Piyasaları, Yenilenebilir Enerji, Dağıtım Sistemi Operatörü, İletim Sistemi Operatörü, Yönetmelik, Şebeke Esnekliği.

\section{Giriş}

Son yıllarda yenilenebilir enerji kaynaklarına (YEK) dayalı elektrik üretim tesislerinin maliyetlerinin azalması ve yenilenebilir enerji üretimini teşvik eden mekanizmalar ile yenilenebilir enerjinin elektrik şebekelerindeki payı hızla artmaya başlamıştır. YEK'lerin miktarının artması, elektrik sistemlerinin talep ve arzdaki değişime yanıt verme kabiliyeti olarak tanımlanan şebeke işletme esnekliğine olan ihtiyacı arttırmaktadır (Koltsaklis vd., 2017: 360-369). Şebekenin esnekliğine olan ihtiyaç, şebeke işletmesinde göz önüne alınan üç temel teknik kısıt (problem) üzerinden açıklanabilir; 1) Arz-talep dengesi: Elektrik şebekelerinde arz ve talep birbirine eşit olmalıdır; 2) Gerilim seviyesi: Şebekenin tüm noktalarında gerilim seviyesi, aşırı yüksek ve aşırı düşük gerilim limitlerinin arasında olmalıdır; 3) Yüklenme seviyesi: Şebekenin ekipmanları termik yüklenme kapasitelerinin üzerinde yüklenmemelidir. Yazarlar tarafından oluşturulan Şekil 1'de gösterildiği gibi, şebekenin arz-talep dengesi iletim sistemi operatörlerinin (ISSO) bir 
Tör, O.B. \& H. Oğuz \& S.M. Kısakürek \& E.N. Kurşuncu \& A.O. Köksal (2021), "Talep Birleştiricilerin Rol

Aldığı Elektrik Piyasa Mekanizmaları ve Türkiye'deki Mevcut Durum Analizi”, Sosyoekonomi, 29(49), 307-322.

problemi iken, gerilim ve yüklenme seviyesi hem İSO'nun hem de dağıtım sistemi operatörlerinin (DSO) ortak problemidir.

\section{Şekil: 1}

Şebeke İşletmesinde Göz Önüne Alınan Üç Temel Teknik Kısıt (bb: Birim Başına)

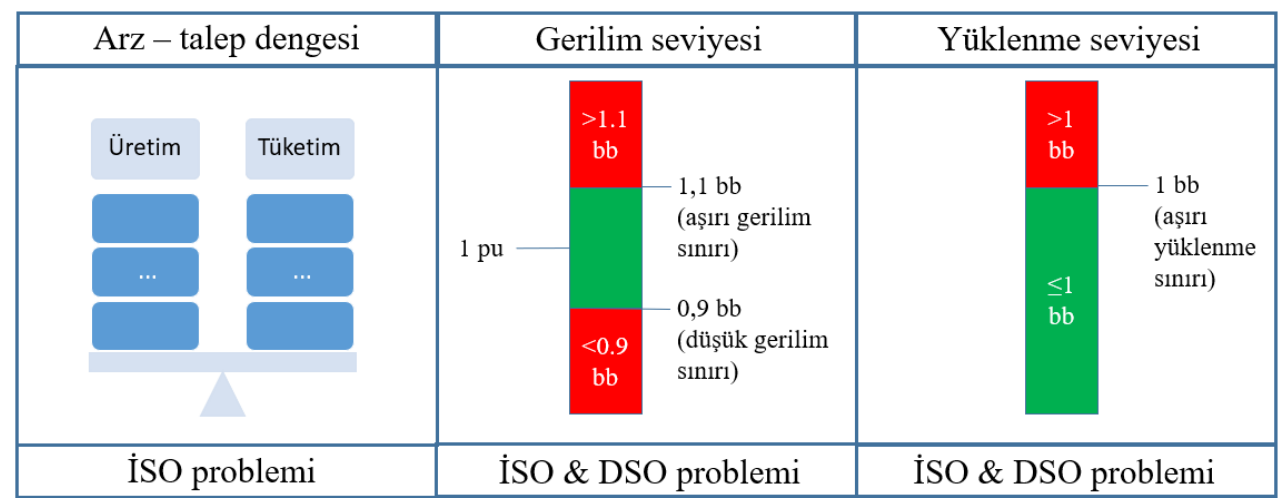

İletim şebekesinde meydana gelen bu temel teknik kısıtlar iletim şebekesine bağlı santrallere verilebilecek talimatlar ile çözülebilirken (örneğin Türkiye'de Gün Öncesi Piyasası (GÖP) ve Gün İçi Piyasasında (GIP) santrallere verilen Yük Al (YAL) ve Yük At (YAT) talimatları (redispatch) gibi (Kocaarslan \& Tiryaki, 2015, 2-11), dağıtım şebekesinde meydana gelen bu işletimsel teknik kısttlar ancak tüketim veya üretim kesintisi ile çözülebilir. Zira, dağıtım şebekelerindeki iletim seviyesine benzer şekilde işleyen bir elektrik piyasası bulunmamaktadır. Bunun en önemli sebebi, dağıtım şebekesine bağlı santrallerin çoğunlukla, üretim seviyesi kontrol edilemeyen (veya üretim kısma yönünde kontrol edilebilen) YEK'e dayalı santraller olması ve üretim seviyesi kontrol edilebilen konvansiyonel santrallerin (doğal gaz, kömür, barajlı hidrolik santraller gibi) miktarının ve kapasitelerinin oldukça sınırlı olmasıdır. Bununla birlikte, gelecekte depolama sistemlerinin dağıtım şebekelerindeki miktarı arttıkça, dağıtım sistemlerinde de benzer bir piyasanın oluşması beklenmektedir (Olivella vd., 2018, 822-840).

İletim şebekesinde meydana gelen teknik kısıtların, şebekeye bağlı konvansiyonel santrallere verilebilecek talimatlar ile çözülemediği durumlarda İSO, tüketim veya üretim kesintisi yapmak zorunda kalabilir. Doğal gaz arzının yetersiz kaldığı kış aylarında doğal gaz santrallerinin üretim miktarındaki düşüşü nedeniyle, elektrik arz - talep dengesinin elektrik talep kesintisiyle sağlanması buna bir örnek olarak verilebilir. Diğer yandan, sistem yükününün minimum seviyede olduğu zamanlarda, YEK'e dayalı üretimin maksimum seviyede gerçekleşmesi durumunda, konvansiyonel üretim santrallerinin güvenli minimum yüklenme seviyesi kısıtlarından dolayı, YEK'e dayalı bazı santrallerin üretiminde zorunlu olarak kesintiye gidilmesi üretim kesintisi ihtiyacına bir örnek olarak verilebilir. Sonuç olarak gerek iletim seviyesinde gerekse de dağıtım seviyesinde meydana gelen operasyonel kısıtların çözümünde tüketim veya üretim miktarında kesintiye gidilmesi kaçınılmaz 
Tör, O.B. \& H. Oğuz \& S.M. Kısakürek \& E.N. Kurşuncu \& A.O. Köksal (2021), "Talep Birleştiricilerin Rol

Aldığı Elektrik Piyasa Mekanizmaları ve Türkiye'deki Mevcut Durum Analizi”, Sosyoekonomi, 29(49), 307-322.

olabilmektedir. Şebekenin esnekliği, şebekede meydana gelebilecek teknik kısıtlarda, elektrik tüketiminde veya üretiminde kesintiye gidilmeden veya kesinti kaçınılmazsa bunu piyasa dinamikleri içinde, çözme imkânı sunar.

Şebekedeki teknik kısıtlar nedeniyle tüketimde kesinti yapılmaya ihtiyaç duyulduğu zorunlu hallerde, İSO genellikle önceliği iletim seviyesinden şebekeye bağlı olan büyük sanayi yüklerine vererek etkinliği artırmak ister. Zira, ihtiyaç duyulan kesinti miktarı için gerekli abone ve dolayısıyla toplam elektriksel ekipman anahtarlama (manevra) sayısı, aynı miktarda kesintinin meskenler ve ticarethaneler gibi küçük ölçekli müşterilere uygulandığ 1 duruma göre oldukça sınırlıdır. Bir başka deyişle, iletim seviyesinde tek bir noktada yapılabilecek tüketim veya üretim kesinti miktarı için, dağıtım sistemlerinde birçok farklı noktada kesinti yapmak gerekir. Dolayısıyla, şebekede kesinti ihtiyacının dağıtım seviyesinde karşılanması için talep birleştiricilere (aggregator) ihtiyaç duyulmaktadır (Eid vd., 2015, 1-5).

Dağıtım şebekesindeki üretim ve tüketim noktalarında şebeke esneklik hizmeti veren talep birleştiricilerden hem iletim sistemi operatörleri (üretim/tüketim dengesi, frekans kontrolü, gerilim kontrolü ve kısıt yönetimi açısından), hem de dağıtım sistemi operatörleri (gerilim kontrolü ve kısıt yönetimi açısından) faydalanabilirler (Merino vd., 2016). Bir sistem operatörünün verdiği kararın diğer sistem operatörünü olumsuz etkilememesi, iletim ve dağıtım sistemi operatörleri arasındaki koordinasyona bağlıdır (ENTSO-E, 2015). Dağıtık üretimin büyük oranda orta gerilim (OG) ve alçak gerilim (AG) seviyeden bağlandığı düşünüldüğünde, iletim sistemi operatörlerinin, sistem frekans ve gerilim regülasyonunda ve kısıt yönetiminde, dağıtım şebekesine bağlı üretim ve yük kontrolünü bir hizmet olarak kullanmaya başlaması, dağıtım sistemi işletmesini etkileyecektir. Örneğin, talep birleştiriciler üzerinden piyasada yer alan yük ve dağıtık üretime, iletim operatörü tarafından, sistem kısıtları ve/veya dengeleme amaçlı verilecek olan YAL/YAT talimatları, dağıtım şebekesi üzerinde aşırı yüklenme ve/veya aşırı gerilim yükselmesi/düşümü sorunu yaratabilir. Dolayısıyla, iletim şebekesi için yapılan şebeke analizlerinin, dağıtım şebekesi için de yapılmasına ve iletim ile dağıtım sistem operatörleri arasında mevcuttan daha ileri seviyede bir koordinasyona ihtiyaç vardır (Ochoa vd., 2016, 16-28).

İkinci bölümde, talep birleştiricilerin hizmet verdiği elektrik piyasalarına ve bu piyasalarda talep birleştiricilerin, DSO'nun, İSO'nun ve piyasa işletmecilerinin rollerine odaklanan bu çalışmada, ilk önce talep birleştirici çözümleri içeren uluslararası piyasa mekanizmaları araştırılmıştır. Daha sonra üçüncü bölümde, talep tarafı katılımında Türkiye'deki durum ve mevzuat ele alınmıştır. Son olarak dördüncü bölümde, talep tarafı katılımında ve öneriler geliştirilmiştir.

\section{Talep Birleştirici Çözümleri İçeren Uluslararası Piyasa Mekanizmaları}

Avrupa'daki talep tarafı katılımı potansiyelinin açığa çıkarılmasında Avrupa Komisyonu'nun Temiz Enerji Paketi'nin Kasım 2016'da yayınlanması etkili olmuştur (European Commission, 2019). Günümüzde $20 \mathrm{GW}$ olan piyasadaki aktif talep tarafı 
katılımı için Avrupa Komisyonunun 2030 hedefi 160 GW'tır (ENTSO-E, 2014). 2017 yılında ENTSO-E puant yükü $581 \mathrm{GW}$ ile 18.01.2017'de gerçekleşmiştir. SDEC (Smart Energy Demand Coalition / Akıllı Enerji Talep Koalisyonu) her y1l Avrupa ülkelerinde talep tarafı katılımın güncel durumunu analiz etmektedir (Smart Energy Europe, 2019). Bu kapsamda SDEC'nin bir önceki raporundan bu yana, talep tarafı katılımının hiç olmadığı bazı ülkelerde bile bu potansiyelin ortaya çıkması için bazı mevzuat çalışmaları yapılmıştır. Avrupa'da talep tarafı katılımının en aktif kullanıldığı ülkeler; Fransa, Almanya, İsviçre, Belçika, Finlandiya, Büyük Britanya ve İrlanda'dır. Birleştiriciler üzerinden sağlanan talep tarafı katılımının iyi işlediği bu ülkelerde bile, halen piyasa mekanizmaları ve ilgili mevzuat düzenlemelerine yönelik gelişmeler devam etmektedir (SEDC, 2017). Bu ülkelerde ve Amerika Birleşik Devletleri'nde (A.B.D) genel trend, talep tarafı katılımının İSO tarafından işletilen merkezi yan hizmetler piyasa modeli ile piyasaya girmesi ve DSO'ların rolleri ve sorumlulukları arttıkça, entegre esneklik piyasa modeline geçmektir (Şekil: 1). Talep birleştiriciler için açılan merkezi yan hizmetler piyasa modeli ve uygulamaları da ülkeler arasında farklılıklar göstermektedir (Tablo: 1).

\section{Şekil: 1 \\ Talep Birleştiricilerin Rol Aldığı Piyasa Modelleri - Genel Trend}
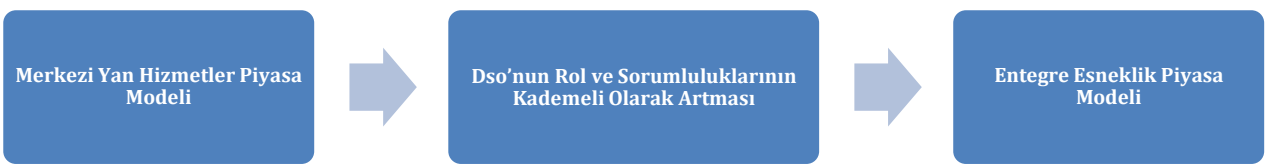

Kaynak: Smart Energy Europe (2019) <http://www.smarten.eu>, 19.11.2019.

Tablo: 1

Bazı Avrupa Ülkelerinde Talep ve Dağıtık Üretim Birleştiricilerin Hizmet Verdikleri Piyasalar

\begin{tabular}{|c|c|c|c|}
\hline & Gün öncesi piyasası & Gün içi piyasası & Dengeleme ve yan hizmetler \\
\hline Almanya & $\begin{array}{r}\text { Dağttık üretim } \sqrt{ } \\
\text { Tüketim } \sqrt{ } \\
\end{array}$ & $\begin{array}{r}\text { Dağıtık üretim } \sqrt{ } \\
\text { Tüketim } \sqrt{ }\end{array}$ & $\begin{array}{r}\text { Dağıtık üretim } \sqrt{ } \\
\text { Tüketim } \sqrt{ }\end{array}$ \\
\hline Belçika & $\begin{array}{r}\text { Dağıtık üretim } \mathbf{X} \\
\text { Tüketim } \sqrt{ }\end{array}$ & $\begin{array}{r}\text { Dağıtık üretim X } \\
\text { Tüketim } \mathbf{X} \\
\end{array}$ & $\begin{array}{r}\text { Dağıtık üretim } \sqrt{ } \\
\text { Tüketim } \sqrt{ }\end{array}$ \\
\hline Büyük Britanya & $\begin{array}{r}\text { Dağıtık üretim } \sqrt{ } \\
\text { Tüketim } \mathbf{X}\end{array}$ & $\begin{array}{r}\text { Dağıtık üretim } \sqrt{ } \\
\text { Tüketim } \mathbf{X} \\
\end{array}$ & $\begin{array}{r}\text { Dağıtık üretim } \sqrt{ } \\
\text { Tüketim } \sqrt{ }\end{array}$ \\
\hline Danimarka & $\begin{array}{r}\text { Dağıtık üretim } \sqrt{ } \\
\text { Tüketim } \sqrt{ }\end{array}$ & $\begin{array}{r}\text { Dağıtık üretim } \sqrt{ } \\
\text { Tüketim } \sqrt{ }\end{array}$ & $\begin{array}{r}\text { Dağıtık üretim } \sqrt{ } \\
\text { Tüketim } \sqrt{ }\end{array}$ \\
\hline Fransa & $\begin{array}{r}\text { Dağıtık üretim } \sqrt{ } \\
\text { Tüketim } \sqrt{ } \\
\end{array}$ & $\begin{array}{r}\text { Dağıtık üretim } \sqrt{ } \\
\text { Tüketim } \sqrt{ }\end{array}$ & $\begin{array}{r}\text { Dağıtık üretim } \sqrt{ } \\
\text { Tüketim } \sqrt{ }\end{array}$ \\
\hline İspanya & $\begin{array}{r}\text { Dağıtık üretim } \mathbf{X} \\
\text { Tüketim } \mathbf{X} \\
\end{array}$ & $\begin{array}{r}\text { Dağıtık üretim } \mathbf{X} \\
\text { Tüketim } \mathbf{X} \\
\end{array}$ & $\begin{array}{r}\text { Dağıtık üretim } \sqrt{ } \\
\text { Tüketim } \sqrt{ }\end{array}$ \\
\hline İsveç & $\begin{array}{r}\text { Dağıtık üretim } \sqrt{ } \\
\text { Tüketim } \sqrt{ }\end{array}$ & $\begin{array}{r}\text { Dağıtık üretim } \sqrt{ } \\
\text { Tüketim } \sqrt{ }\end{array}$ & $\begin{array}{r}\text { Dağıtık üretim } \sqrt{ } \\
\text { Tüketim } \sqrt{ }\end{array}$ \\
\hline İtalya & $\begin{array}{r}\text { Dağıtık üretim } \mathbf{X} \\
\text { Tüketim } \mathbf{X}\end{array}$ & $\begin{array}{r}\text { Dağıtık üretim X } \\
\text { Tüketim X } \\
\end{array}$ & $\begin{array}{r}\text { Dağıtık üretim } \mathbf{X} \\
\text { Tüketim } \mathbf{X}\end{array}$ \\
\hline Polonya & $\begin{array}{r}\text { Dağıtık üretim } \sqrt{ } \\
\text { Tüketim } \sqrt{ } \\
\end{array}$ & $\begin{array}{r}\text { Dağıtık üretim } \sqrt{ } \\
\text { Tüketim } \sqrt{ } \\
\end{array}$ & $\begin{array}{r}\text { Dağıtık üretim } \mathbf{X} \\
\text { Tüketim } \mathbf{X}\end{array}$ \\
\hline Slovenya & $\begin{array}{r}\text { Dağıtık üretim } \mathbf{X} \\
\text { Tüketim } \mathbf{X}\end{array}$ & $\begin{array}{r}\text { Dağıtık üretim } \mathbf{X} \\
\text { Tüketim } \mathbf{X}\end{array}$ & $\begin{array}{r}\text { Dağıtık üretim } \sqrt{ } \\
\text { Tüketim } \sqrt{ }\end{array}$ \\
\hline Türkiye & $\begin{array}{r}\text { Dağıtık üretim } \mathbf{X} \\
\text { Tüketim } \mathbf{X} \\
\end{array}$ & $\begin{array}{r}\text { Dağıtık üretim } \mathbf{X} \\
\text { Tüketim } \mathbf{X} \\
\end{array}$ & $\begin{array}{r}\text { Dağıtık üretim } \mathbf{X} \\
\text { Tüketim } \mathbf{X} \\
\end{array}$ \\
\hline
\end{tabular}

Kaynak: Smart Energy Europe (2019) <http://www.smarten.eu>, 19.11.2019. 
Tablo: 1'de görüldüğü üzere, birçok Avrupa ülkesinde talep ve dağıtık üretim birleştiriciler farklı piyasalarda yer almaya başlamıştır. Almanya, Fransa, Danimarka ve İsveç’te talep ve dağıtık üretim birleştiriciler her üç piyasada da (gün öncesi, gün içi, dengeleme ve yan hizmetler) faaliyet göstermektedir. Bazı ülkelerde ise sadece belli piyasalarda yer almaktadırlar. İtalya ve Türkiye'de ise talep ve dağıtık üretim birleştiriciler henüz herhangi bir piyasada yer almamaktadır.

\subsection{Merkezi Yan Hizmetler Piyasa Modeli}

Birçok Avrupa ülkesinde ve ABD'de talep birleştiriciler piyasaya merkezi yan hizmetler piyasa modeli ile giriş yapmıştır. $\mathrm{Bu}$ modelde İSO yan hizmetler piyasasında, iletim seviyesinden bağlı üreticiler ve tüketiciler doğrudan, dağıtım şebekesine bağlı olan dağıtık enerji kaynaklarından ve tüketicilerden ise talep birleştiriciler üzerinden hizmet alır. DSO'lar, İSO tarafindan işletilen yan hizmetlerin tedariki ve aktivasyonu süreçlerine dâhil değildir. Yazarlar tarafindan oluşturulan Şekil: 3'te de gösterildiği gibi DSO'lar sadece, dağıtım şebekesindeki kaynakların İSO tarafından işletilen yan hizmetler piyasasında aktivasyonunun, dağıtım şebekesinde teknik kısıtlara yol açmamasını garanti etmek için, bir ön yeterlilik sürecine dâhildir.

Şekil: 3

Merkezi Yan Hizmetler Piyasa Modeli (Mekanizmanın Mimari Yapısı ve Roller)

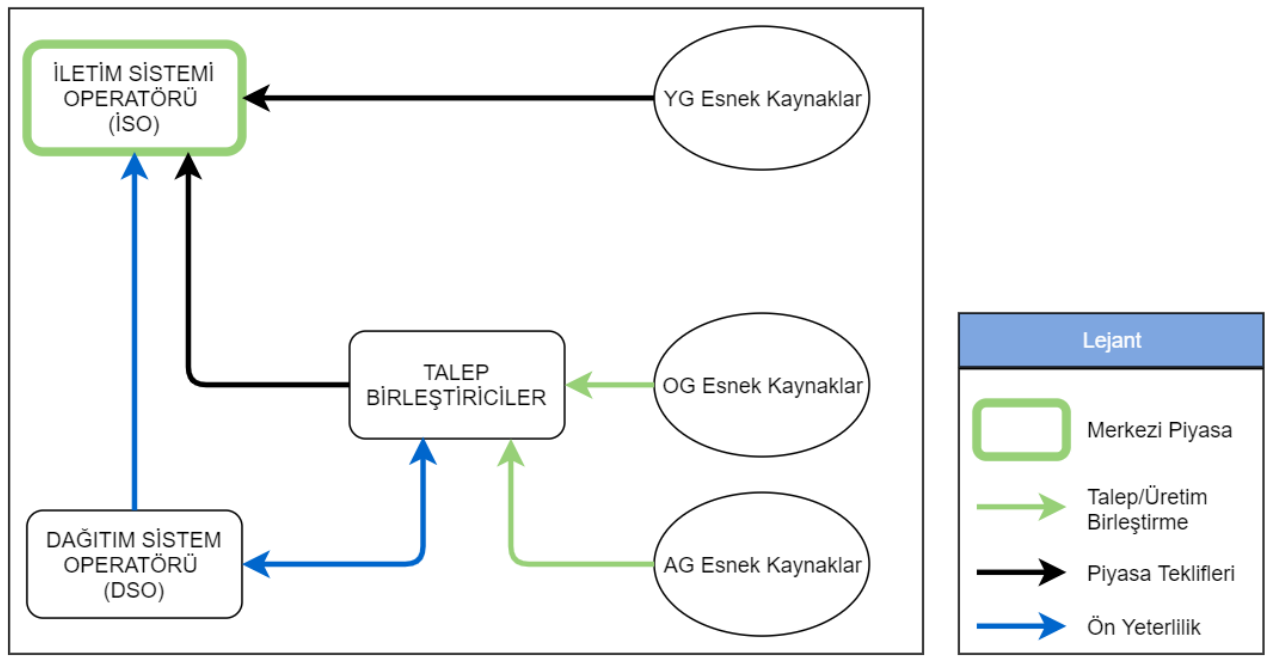

Dağıtım şebekesine bağlı kaynakların İSO tarafından yan hizmetler piyasasında işletildiği bu modelde DSO'nun bu ön yeterlilik sürecinde etkin rol alması, İSO tarafindan talep birleştiricilere verilen talimatların dağıtım şebekesinde teknik kısıtlara yol açmaması açısından önemlidir. Zira, İSO'dan gelecek talimatlar OG şebekede gerilim düşümü veya yükselmesi problemine neden olabilir. Bu problem özellikle de son yıllarda sayıları önemli 
oranda artış gösteren ve artmaya devam eden PV güneş santralleri sonrası daha da bir önem kazanmaktadır. Bu konuda Adıyaman Kahramanmaraş Dağıtım A.Ş. (AKEDAŞ) şebekesinde gerçekleştirilen simülasyon çalışmalarının sonuçları aşağıda açıklanmıştır.

\subsubsection{Dağıtık Üretim Kaynaklarına Verilecek Üretim Kesinti Talimatı Sonrası OG Şebekede Yaşanabilecek Gerilim Düşümü Problemi}

AKEDAŞ şebekesini besleyen Doğanköy Transformatör Merkezi (TM) den çıkan Elbistan Köyler OG fideri üzerinde oldukça fazla PV güneş santrali bulunmaktadır (Şekil: 4). Bu santrallerin bir talep birleştirici üzerinden yan hizmetler piyasasında rol aldıklarını ve iletim şebekesinde meydana gelebilecek bir kısıtta İSO’ya (Türkiye'de TEİAŞ - Türkiye Elektrik İletim A.Ş) üretim kesinti hizmeti verdiğini varsayalım. İletim şebekesinde böyle bir kısıt sonrası bir talep birleştirici tarafından bu fider üzerindeki tüm üretimin kesilmesi yönünde bir talimat gelirse, fider üzerindeki OG/AG dağıtım trafo merkezlerinde gerilim düşümü \%10'u aşmaktadır (Şekil: 5). Elektrik dağıtım şebekelerinde gerilim düşümü ve yükselmesinde uluslararası genel kabul gören işletme kriteri \%10'dur. Dolayısıyla, elektrikli cihazlar tasarlanırken, şebeke geriliminin $\pm \% 10$ bandında değişebileceği göz önüne alınır. İlgili yönetmeliklerde açıkça belirtilmesi gereken bu sınır Türkiye'de de \%10 uygulanmaktadir.

Şekil: 4

\section{Doğanköy TM Elbistan Köyler Fideri (Kırmızı Daire İçerisinde Gösterilen Fider)}

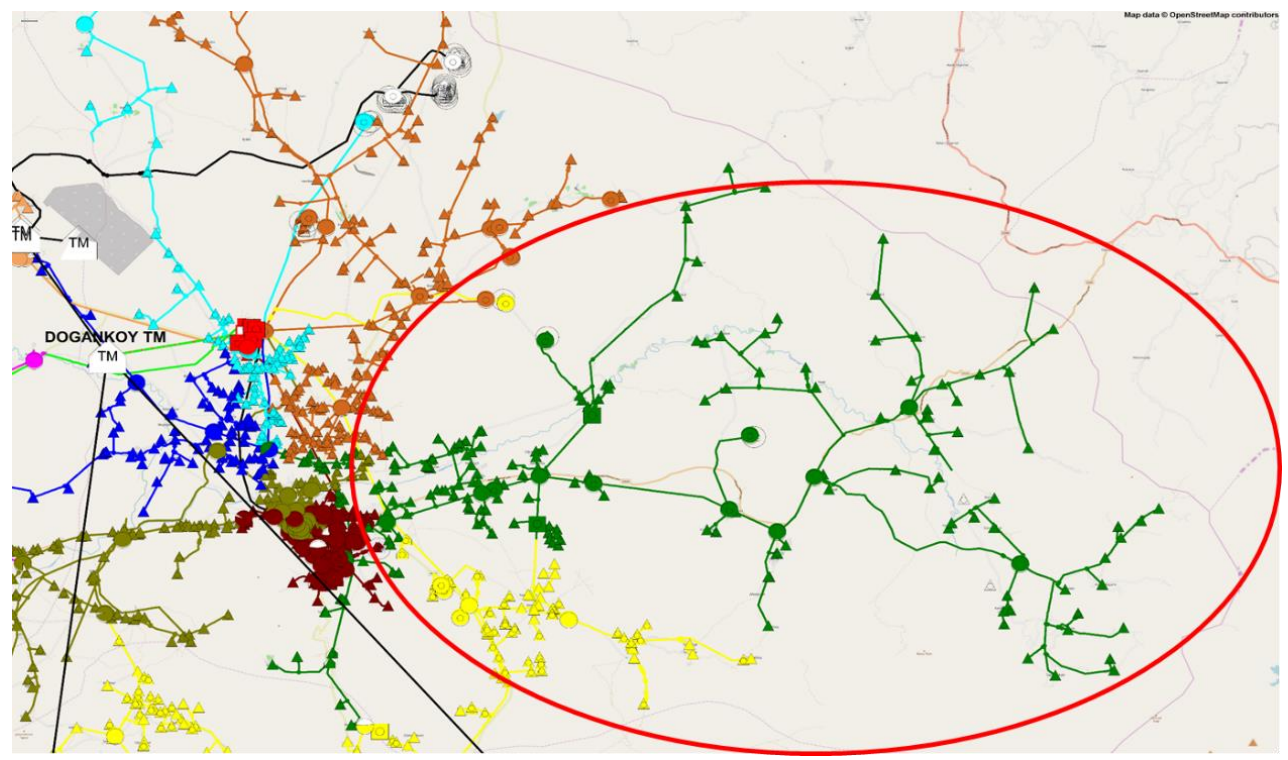


Şekil: 5

Doğanköy TM Elbistan Köyler Fideri

(íSO Talimatı Öncesi ve Sonrası Durumlarında Yük Akış Analiz Sonuçları)

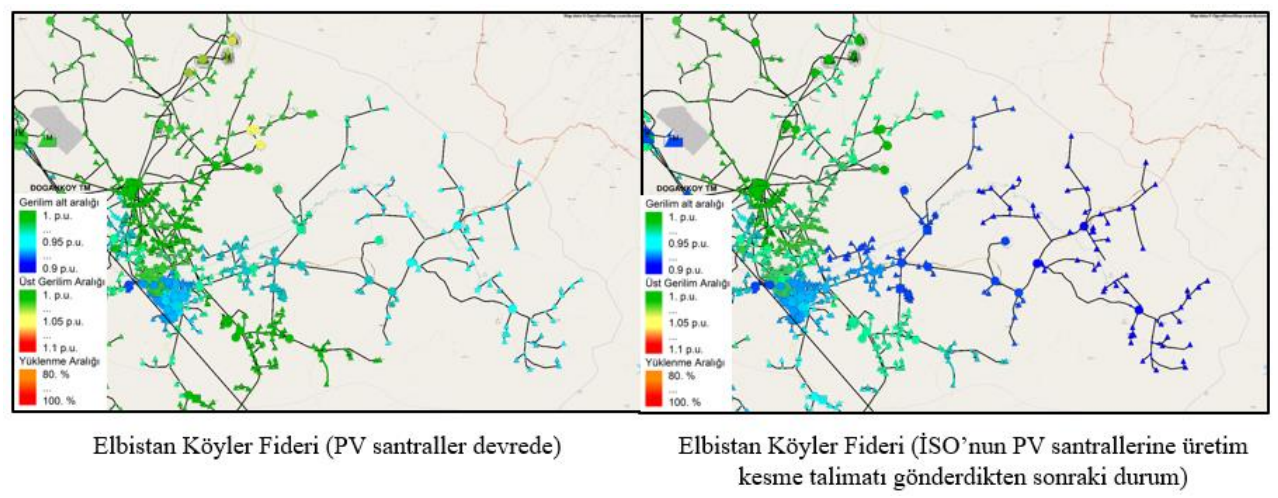

\subsubsection{Abonelere Verilebilecek Tüketim Kesinti Talimatı Sonrası OG Şebekede Yaşanabilecek Gerilim Yükselmesi Problemi}

Bu senaryoda ise, Adıyaman TM Çelikhan OG fideri üzerinde TEİAŞ tarafından yük kesinti talimatı geldiği durumda yaşanan gerilim yükselmesi problemi incelenmiştir. Şekil: 6'da gösterilen Çelikhan OG fideri birçok sanayi yükünü beslemektedir ve fider üzerinde önemli miktarda PV üretim santrali bulunmaktadır. Bu sanayi yüklerinin bir talep birleştirici üzerinden yan hizmetler piyasasında rol aldıklarını ve iletim şebekesinde meydana gelebilecek bir kısıtta TEİAŞ'a tüketim kesinti hizmeti verdiğini varsayalım. İletim şebekesinde böyle bir kısıt sonrası talep birleştirici tarafından bu fider üzerindeki sanayi yüklerinin elektriğinin kesilmesi yönünde bir talimat gelirse, fider üzerindeki OG/AG dağıtım trafo merkezlerinde gerilim yükselmesi \%10’u aşmaktadır (Şekil: 7). 
Şekil: 6

Adıyaman TM Çelikhan Fideri (Kırmızı Daire İçerisinde Gösterilen Fider)

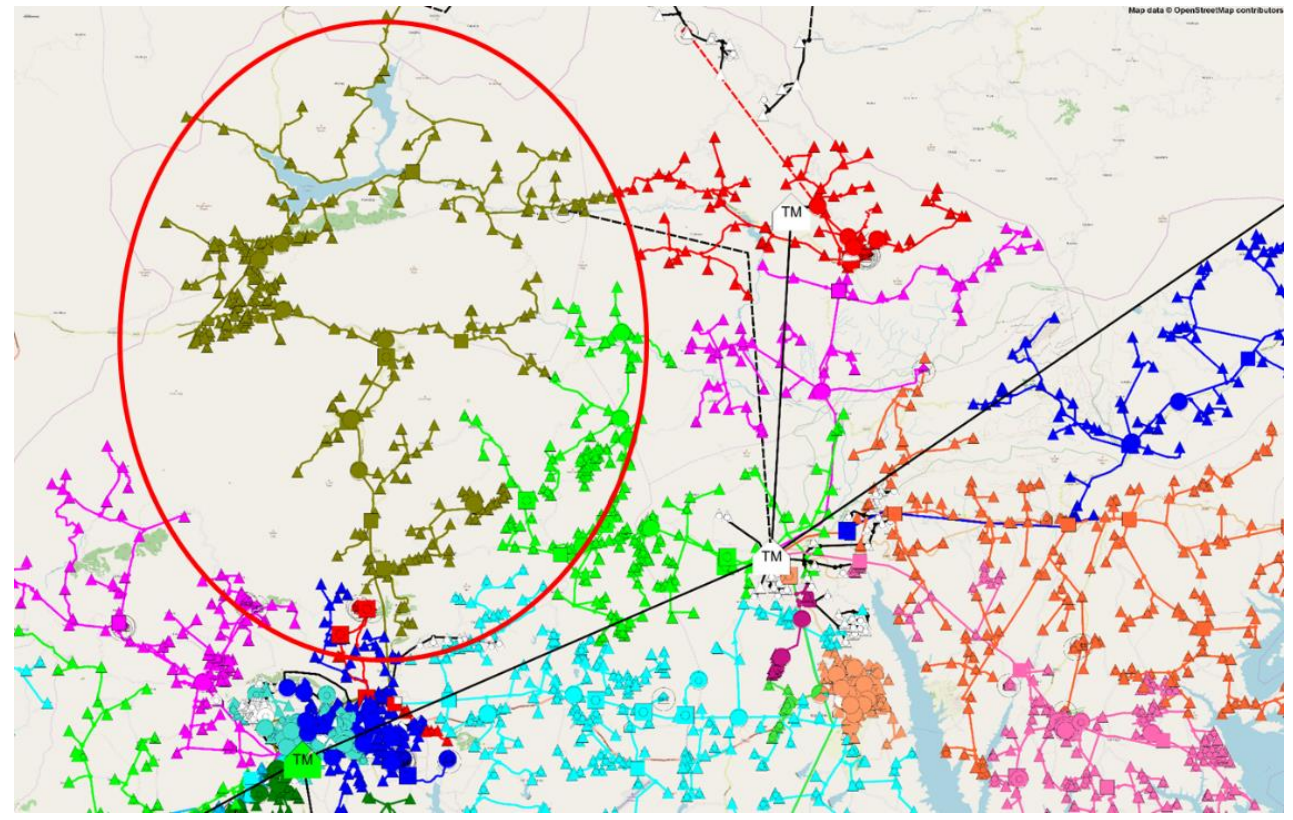

Sekil: 7

Adıyaman TM Çelikhan Fideri

(Yük Kısma Talimatı Sonrası ve Öncesi Durumlardaki Analiz Sonuçları)

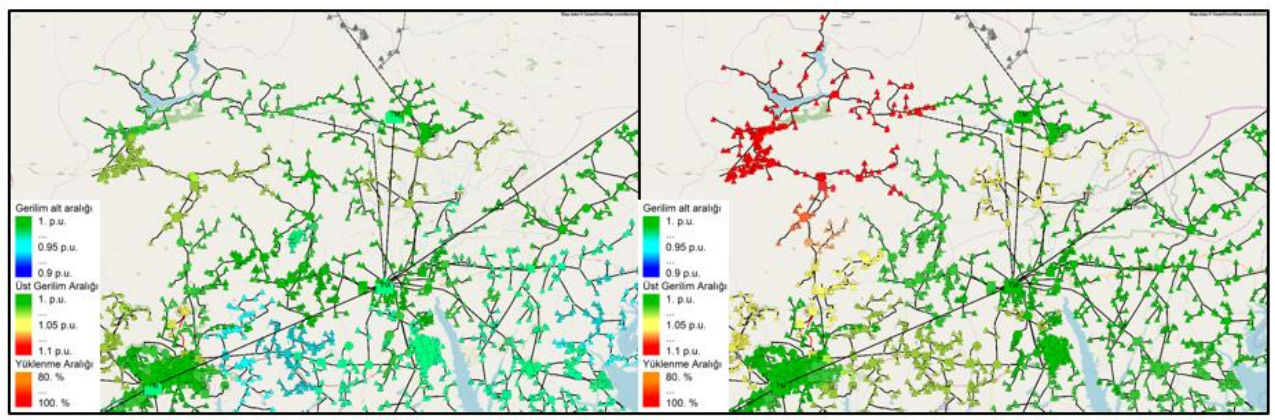

İSO'nun sanayi yüklerine tüketim kesme talimatı göndermeden önceki durum

İSO'nun sanayi yüklerine tüketim kesme talimatı gönderdikten sonraki durum

\subsection{Yerel Yan Hizmetler Piyasa Modeli}

$\mathrm{Bu}$ modelin temel özeliği yerel piyasanın DSO'lar tarafından işletilmesidir. Bu modelde İSO dağıtım şebekesi kaynaklarına ancak bu yerel piyasa üzerinden erişebilir. DSO 
yerel kullanım için gerekli teklifleri seçip birleştirir ve kalan teklifleri İSO piyasasına aktarır. DSO’nun esnek kaynakların yerel şebeke için kullanılmasında önceliği vardır.

$\mathrm{Bu}$ modelde paydaşların rolleri, piyasa tasarımı ve oyuncular arasındaki etkileşim, yazarlar tarafından oluşturulan Şekil: 8'de gösterilmektedir. Yerel yan hizmetler piyasa modelinin merkezi yan hizmetler piyasa modeline kıyasla temel farkı, yerel piyasayı teşvik etmesidir. Bu modelde dağıtım şebekesine bağlı olan ve talep birleştiriciler üzerinden şebeke esneklik hizmeti verebilen kaynakların öncelikle DSO tarafından ve bir piyasa üzerinden kullanılması esastır.

Şekil: 8

Yerel Yan Hizmetler Piyasa Modeli (Mekanizmanın Mimari Yapısı ve Roller)
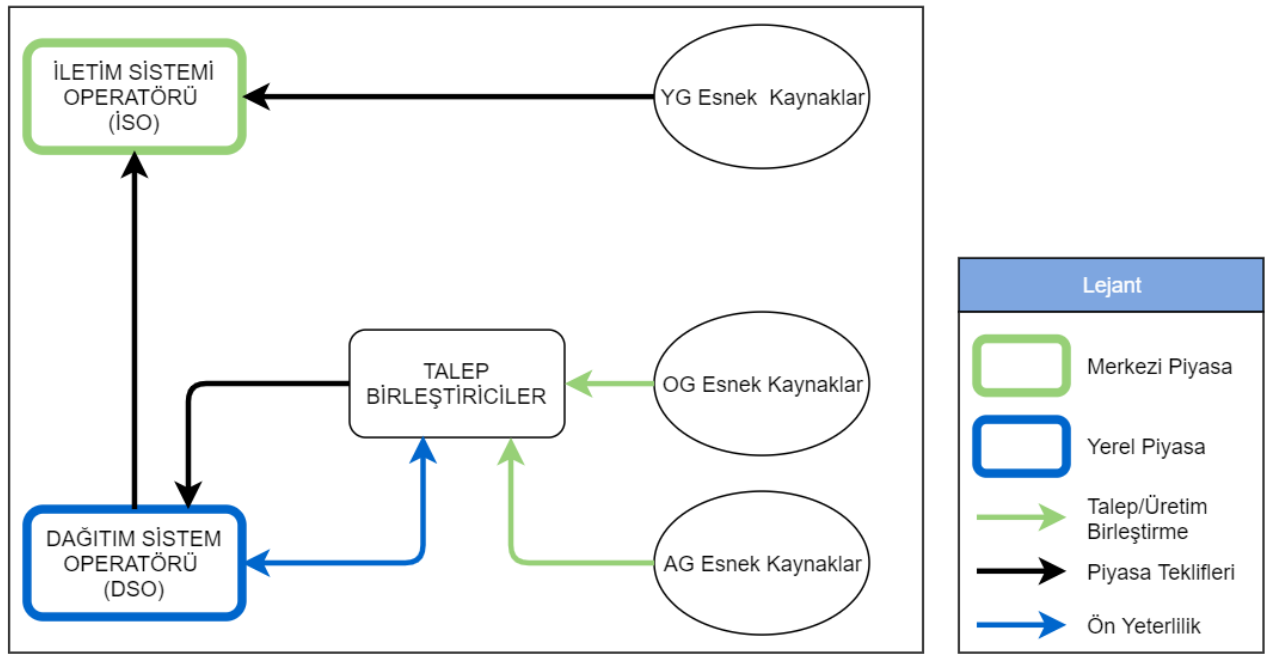

Yerel yan hizmetler piyasa modelinin henüz bir uygulama örneği olmamakla birlikte, dağıtım şebekesindeki esnek üretim ve tüketim kaynaklarının DSO tarafından işletilen bir piyasada kullanılabileceğini göstermesi açısından önemlidir. Zira, dağıtım şebekelerinin bilindik pasif (tek yönlü yük akışı) karakteristiği, dağıtık üretim kaynaklarının artışı ile birlikte, aynı iletim sisteminde olduğu gibi, aktif (çift yönlü yük akışı) bir karakteristiğe dönüşmektedir. Dolayısıyla, dağıtım şebekelerine esneklik sağlayan çözümlere olan ihtiyaç her geçen gün daha da artmaktadır. İleride böyle bir piyasanın oluşması sonrası DSO'ların alacakları hizmeti optimize etmesi - yani dağıtım şebekesinde oluşan teknik kısıtı minimum maliyet ile gidermesi - gerekecektir. Bu konuda AKEDAŞ şebekesinde gerçekleştirilen bilgisayar simülasyon çalışmaları aşağıdaki alt başlıklarda açıklanmıştır. Bilgisayar simülasyonları DigSilent PowerFactory ${ }^{\mathrm{TM}}$ şebeke analiz yazılımı ile gerçekleştirilmiştir. Bu amaçla AKEDAŞ elektrik dağıtım şebekesinin coğrafi bilgi sistemi (CBS) veritabanındaki şebeke verileri kullanılarak şebekenin yük akış modeli oluşturulmuştur. Yük akış 
Tör, O.B. \& H. Oğuz \& S.M. Kısakürek \& E.N. Kurşuncu \& A.O. Köksal (2021), "Talep Birleştiricilerin Rol

Aldığı Elektrik Piyasa Mekanizmaları ve Türkiye'deki Mevcut Durum Analizi”, Sosyoekonomi, 29(49), 307-322.

simülasyonları ile şebekedeki teknik kısıtlar (aşırı yüklenme ve aşırı gerilim düşümü/yükselmesi) analiz edilmiştir.

\subsubsection{OG Hattında Așırı Yüklenme Probleminin Giderilmesine Yönelik Talep Birleştiricilerden Alınan Kesinti Hizmetinin Optimize Edilmesi}

AKEDAŞ şebekesinde Raven (1/0) bir OG hattın \%121 yüklendiğini (hattın kapasitesi: 12,55 MW; yüklenmesi: 15,18 MW), bu hat üzerinden beslenen abonelerin bir talep birleştirici tarafından kesinti esnekliği hizmeti verdiğini ve abonelerin kesinti için, fider üzerindeki her bir OG/AG transformatör bazında, farklı bir bedel talep ettiklerini varsayalım. Fider üzerindeki transformatörler bazında yük kesintisi için abonelerin talep ettiği bedel (TL/MWh), kesinti talimatı öncesi abonelerin yükü (MWh) ve optimum kesinti miktarı Tablo: 2'de gösterilmiştir. Tablodan da görüleceği üzere, OG hattın yükünü kapasitesi seviyesine indirene kadar, en uygun fiyat talep eden abonelerden başlayarak, kesinti yapılmıştır.

Tablo: 2

\section{OG Hattında Aşırı Yüklenme Probleminin Talep Birleştiricilerden Alınan Kesinti Hizmeti ile Optimize Edilmesi}

\begin{tabular}{|c|c|c|c|c|}
\hline $\begin{array}{l}\text { Aşırı yüklenen OG hat } \\
\text { üzerindeki transformatör }\end{array}$ & $\begin{array}{l}\text { Yük kesintisi için talep } \\
\text { edilen bedel (TL/MWh) }\end{array}$ & $\begin{array}{c}\text { Kesinti talimatı } \\
\text { oncesi yük (MWh) }\end{array}$ & $\begin{array}{c}\text { Kesinti talimatı } \\
\text { sonrası yük (MWh) }\end{array}$ & Kesinti talimatı (\%) \\
\hline OG/AG Transformatör 1 & En düşük & 2,06 & 0,00 & $100 \%$ \\
\hline OG/AG Transformatör 2 & > OG/AG Transformatör 1 & 0,05 & 0,00 & $100 \%$ \\
\hline OG/AG Transformatör 3 & > OG/AG Transformatör 2 & 4,22 & 3,70 & $12 \%$ \\
\hline OG/AG Transformatör 4 & > OG/AG Transformatör 3 & 2,57 & 2,57 & $0 \%$ \\
\hline OG/AG Transformatör 5 & > OG/AG Transformatör 4 & 2,06 & 2,06 & $0 \%$ \\
\hline OG/AG Transformatör 6 & > OG/AG Transformatör 5 & 1,65 & 1,65 & $0 \%$ \\
\hline OG/AG Transformatör 7 & En yüksek & 2,57 & 2,57 & $0 \%$ \\
\hline Toplam & & 15,18 & 12,55 & \\
\hline
\end{tabular}

Tablo: 2'de görüldüğü üzere, DSO'nun o aşırı yüklenme yaşanan daatte toplam kesinti ihtiyacı $15,18-12,55=2,63$ MWh'tır. Kesinti için en uygun fiyat verilmiş olan OG/AG Transformatör 1'in o saatteki toplam yükü 2,06 MWh'tır. Dolayısıyla, OG/AG Transformatör 1'in tüm yükü kesilmiştir. Fakat, bu yeterli olmadığı için, ikinci en ucuz teklifi vermiş olan OG/AG Transformatör 2'in tüm yükü (0,05 MWh) ve üçüncü en ucuz teklifi vermiş olan OG/AG Transformatör 1'den 0,52 MWh kesinti yapılmıştır. Böylece toplam kesinti 2,06 +0,05 +0,52 = 2,63 MWh'tır.

\subsubsection{OG/AG Transformatörün Aşırı Yüklenmesi Durumlarında DSO’nun Transformatörden Beslenen Abonelere Optimum Kesinti Talimatı Göndermesi}

Bu bölümde, OG/AG transformatörlerinin aşırı yüklenmesi durumlarında, DSO’nun bir talep birleştirici üzerinden abonelere optimum kesinti talimatı göndermesi senaryosu analiz edilmiştir. Transformatörlerin yılda kısa bir zaman dilimi (5-10 saat) aşırı yüklenmesinden dolayı transformatörde güç artırımı gerekebilmektedir. Güç artırımı için şehir merkezinde uygun trafo merkezi bulunmasının zor olabilmektedir. Bu sebeple talep 
kontrolü ile puant saatlerinde yük kısma problemin çözülerek yatırım ihtiyacının önüne geçilebilecek veya yatırım ertelenebilecektir.

$\mathrm{Bu}$ amaçla gerçekleştirilen analizlerde, $1250 \mathrm{kVA}$ kapasiteli bir OG/AG transformatörün \%120 yüklendiği (1512 kVA yük) ve OG/AG transformatörün beslediği abonelerin kesinti talep ettiği bedelin eşit olduğunu varsayalım. Bu durumda DSO'nun OG/AG transformatöre en uzak noktalardaki abonelerde kesinti yapması beklenir (teknik kayıpları minimize etmek için). Nitekim optimizasyon sonucuna göre, OG/AG transformatörün yükü 1250 kVA'ya düşünceye kadar, transformatöre en uzak noktalardan başlamak suretiyle, abonelerde kesinti yapılmıştır (Şekil: 9' da mavi ile gösterilen aboneler).

Şekil: 9

AG Transformatörün Aşırı Yüklenme Probleminin Talep Birleştiricilerden Alınan Kesinti Hizmeti ile Optimize Edilmesi (Kırmızı: OG/AG Transformatör; Mavi: Kesinti Yapılan Aboneler)

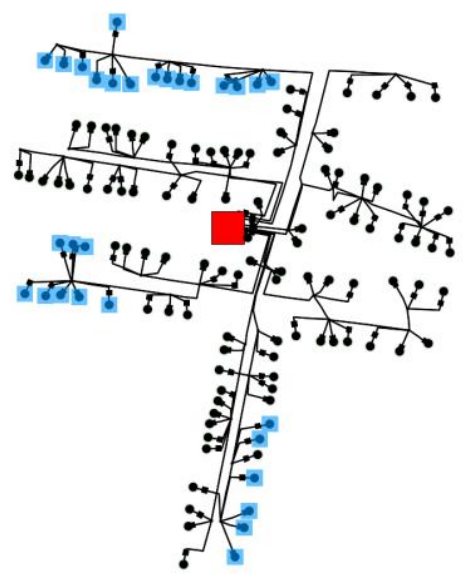

\subsection{Entegre Esneklik Piyasa Modeli}

Entegre esneklik piyasa modelinde İSO ve DSO'lara herhangi bir öncelik verilmemekte ve bir piyasa işletmecisi tarafından işletilen bu modelde kaynaklar en çok fiyatı vermeye istekli olan sistem işletmecine (ISO veya DSO) tahsis edilmektedir. Ayrı bir merkezi veya yerel piyasa bulunmamaktadır. Paydaşların rolleri, piyasa tasarımı ve oyuncular arasındaki koordinasyon yazarlar tarafından oluşturulan Şekil: 10'da gösterilmektedir. Entegre esneklik piyasa modelinin henüz bir uygulama örneği olmamakla birlikte, Şekil: 10'da da gösterildiği gibi, gelişmiş ülkelerde genel trend, talep tarafi katılımının İSO tarafından işletilen merkezi yan hizmetler piyasa modeli ile piyasaya girmesi ve DSO'ların rolleri ve sorumlulukları arttıkça, zamanla entegre esneklik piyasa modeline geçmektir. 
Şekil: 10

Entegre Esneklik Piyasa Modeli (Mekanizmanın Mimari Yapısı ve Roller)

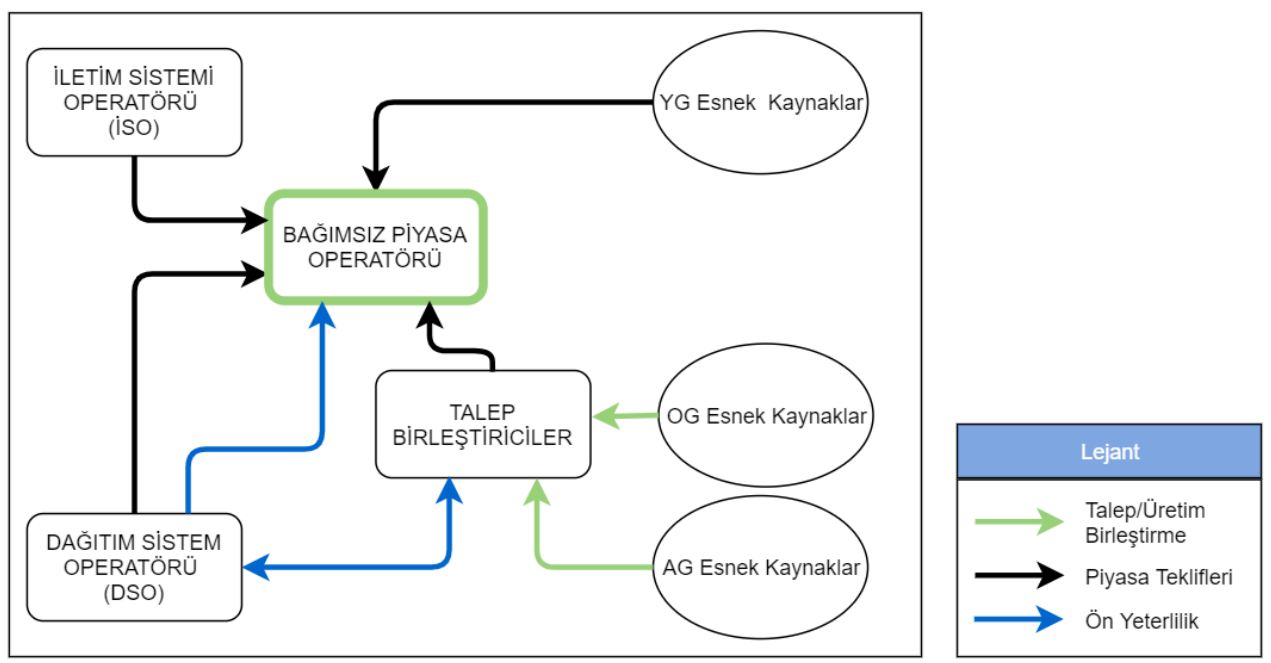

\section{Talep Tarafı Katılımında Türkiye'deki Mevzuat ve Mevcut Uygulamalar}

6446 sayılı Türkiye Elektrik Piyasası Kanunu'nun ilk maddesinde kanunun amac1, elektriğin yeterli, kaliteli, sürekli, düşük maliyetli ve çevreyle uyumlu bir şekilde tüketicilerin kullanımına sunulması için, rekabet ortamında özel hukuk hükümlerine göre faaliyet gösteren, mali açıdan güçlü, istikrarlı ve şeffaf bir elektrik enerjisi piyasasının oluşturulması ve bu piyasada bağımsız bir düzenleme ve denetimin yapılmasının sağlanmasıdır (EPDK, 2019). Türkiye Elektrik Piyasası kanunlarla ve ilgili yönetmeliklerle düzenlenmektedir.

Talep kontrol hizmetinin tedarik esasları, Şebeke Yönetmeliği ve Yan Hizmetler Yönetmeliğinde "anlık talep kontrolü" altında düzenlenmiştir. Yan Hizmetler Yönetmeliğine göre anlık talep kontrol hizmeti sağlayacak iletim sistemine bağlı tüketim tesisleri, anlık talep kontrol yedekleri vasıtasıyla sistem frekansındaki düşmenin önlenmesini sağlar. Anlık talep kontrolünde amaç frekans düşünce, düşük frekans röleleri üzerinden sistem güvenliği için talep tarafının sistemden düşürülmesidir. TEİAŞ'ın Avrupa şebekesi (ENTSO-E) ile entegrasyonu sonucunda ise anlık talep kontrolü işlevini kısmen yitirmiştir (Sanli, 2014).

Şebeke Yönetmeliğine göre, üretim gücünün düşmesi ve/veya iletim sisteminde kesinti ve/veya aşırı yüklenme olması durumunda, işletme yedeklerinin yetersiz kalması nedeniyle kritik veya kararsız işletme koşullarının oluşması halinde veya aşırı gerilim düşmelerinde TEİAŞ ve kullanıcılar tarafından aşağıda belirtilen esaslar çerçevesinde acil durum önlemleri uygulanır: 
Tör, O.B. \& H. Oğuz \& S.M. Kısakürek \& E.N. Kurşuncu \& A.O. Köksal (2021), “Talep Birleştiricilerin Rol Aldığı Elektrik Piyasa Mekanizmaları ve Türkiye'deki Mevcut Durum Analizi”, Sosyoekonomi, 29(49), 307-322.

- Elektrik Piyasası Yan Hizmetler Yönetmeliği kapsamında tüketim tesisi sahibi tüzel kişilerin anlık talep kontrolü hizmeti sağlaması,

- Otomatik olarak düşük frekans röleleri ile yükün kesilmesi,

- TEİAŞ tarafından yükün el ile planlı olarak veya el ile acilen kesilmesi,

- TEİAŞ tarafından iletim sistemi geriliminin tanımlı sınırlar dahilinde düşürülmesi yoluyla talebin azaltılması.

Sonuç olarak, Elektrik Piyasası Yan Hizmetler Yönetmeliği kapsamında tüketim tesisi sahibi tüzel kişiler anlık talep kontrolü hizmeti sağlayabilmekte, Şebeke Yönetmeliğine göre de şebekede yaşanabilecek teknik bir kısıtta TEİAŞ, acil durum önlemleri kapsamında, böyle bir hizmet alabilmektedir. Fakat, piyasa koşullarında henüz böyle bir hizmet alınmamıştır. Yük kesintisi sadece; i) Üretimin tüketimi karşılayamadığı zamanlarda şebeke frekansı belirli seviyelerin altına düştüğünde düşük frekans röleleri üzerinden otomatik olarak, ii) Acil durumlarda TEİAŞ tarafından planlı veya acil yapılmaktadır. Ayrıca, yönetmeliklerde acil durum önlemleri olarak sadece tüketim kesintisi tanımlanmış olup, üretim kesintisi bir acil durum önlemi olarak tanımlanmamıştır. Fakat, özellikle de son yıllarda yenilenebilir enerji santrallerinin şebekedeki kurulu gücünün önemli oranda artış göstermiş olması ve yenilenebilir enerji kaynaklarının ülke politikaları destekleniyor olması, üretim kesintisinin de bir acil durum önlemi olarak değerlendirilmesi gerektiğine işaret etmektedir.

\section{Sonuç ve Öneriler}

Talep birleştirici mekanizmaları tüm ülkelerde iletim seviyesindeki piyasalarda hizmet vermeye başlamıştır. Dağıtım şebekesinde henüz bir talep birleştirici piyasası yoktur ve dolayısıyla talep birleştiricileri için bir piyasa mekanizması tanımlanmamıştır. Bir başka deyişle, talep birleştiriciler, dağıtım şebekesindeki dağıtık üretim ve tüketim abonelerini birleştirerek, İSO'nun işlettiği iletim seviyesindeki piyasalarda hizmet vermeye başlamışlardır (Merkezi Yan Hizmetler Piyasa Modeli). Diğer yandan, DSO'ların dağıtım şebekelerine esneklik sağlayan çözümlere olan ihtiyacı her geçen gün daha da artmaktadır. Zira, dağıtım şebekelerinin bilindik pasif (tek yönlü yük akışı) karakteristiği, dağıtık üretim kaynaklarının artışı ile birlikte aktif (çift yönlü yük akışı) bir karakteristiğe dönüşmektedir. Bu nedenle, gelişmiş piyasalarda genel trend, talep tarafı katılımının İSO tarafından işletilen Merkezi Yan Hizmetler Piyasa Modeli ile piyasaya girmesi ve DSO'larm rolleri ve sorumlulukları arttıkça, zamanla hem İSO'nun hem de DSO'ların şebeke esneklik hizmeti alabileceği bir piyasa modeline geçmektir (Entegre Esneklik Piyasa Modeli).

Talep birleştiricilerin rol alabilecekleri tüm piyasa modellerinde iletim ve dağıtım şirketlerinin koordinasyonuna ihtiyaç bulunmaktadır. Zira, çalışmada gerçekleştirilen simülasyon analizlerinde ve literatürdeki çalışmalarda vurgulandığı gibi, talep birleştirici çözümleri hem iletim hem de dağıtım sistemine önemli bir esneklik kazandırmaktadır. Ancak, özellikle iletim sistemi odaklı talep ve dağıtık üretim birleştirici çözümlerin dağıtım sistemine olumsuz etkileri olabilmektedir. Bu etkileşimin dağıtım sistemine bağlı yenilenebilir enerji kaynaklarının miktarı ile daha da artacağı beklenmektedir. Dolayısıyla, 
Tör, O.B. \& H. Oğuz \& S.M. Kısakürek \& E.N. Kurşuncu \& A.O. Köksal (2021), "Talep Birleştiricilerin Rol

Aldığı Elektrik Piyasa Mekanizmaları ve Türkiye'deki Mevcut Durum Analizi”, Sosyoekonomi, 29(49), 307-322.

iletim şebekesi için yapılan şebeke analizlerinin, dağıtım şebekesi için de yapılmasına ve iletim ile dağıtım sistem operatörleri arasında mevcuttan daha ileri seviyede bir koordinasyona ihtiyaç vardır.

Elektrik piyasalarında Bölgesel fiyat uygulamaları, talep birleştirici mekanizmaların yaygınlaşmasında önemli bir etkendir. Türkiye'deki elektrik piyasasında henüz Bölgesel fiyat uygulaması yoktur. Dolayısıyla, Dengeleme Güç Piyasasında belirlenen fiyatlar tüm bölgeler için eşittir ve şebekedeki kısıtların maliyetleri tüm kullanıcılara yansıtılmaktadır. Ayrıca, aynı uzlaştırma dönemi içindeki artı ve eksi yöndeki dengesizlikler birbirini dengelemekte, yani mali bir sorumluluk getirmemektedir. Buna ilave olarak, iletim şebekesindeki kısıtlar nedeniyle elektrik kesintisi gerektiren tüm durumlar "acil durum" olarak tanımlanmakta ve dolayısıyla da herhangi bir mali yükümlülük getirmemektedir. Bu koşullarda talep birleştiricilerin iletim seviyesindeki piyasalara girmeleri neredeyse imkânsız görünmektedir.

Türkiye'de talep birleştiricilerin rol alacağı piyasaların gelişmesi için öncelikle, talep tarafı katılımının, Avrupa ve Amerika'daki örneklerinde olduğu gibi, iletim seviyesindeki piyasalarda (Gün Öncesi, Gün İçi, Dengeleme ve Yan Hizmetler) yer alması sağlanmalıdır. Yani, talep tarafı katılımı düşük frekans röleleri ile otomatik veya acil durumlarda talimatla aktive edilen anlık talep kontrolü ile sınırlı kalmamalıdır. Büyük sanayi yükleri ile başlamak gerekir. Talep birleştiriciler öncelikle büyük sanayi yüklerine hizmet vermeye başlayacak ve piyasadaki ihtiyaç doğrultusunda zamanla mesken ve ticarethaneleri de portföylerine katacaktır. Dağıtım seviyesinde portföy oluştukça, talep birleştiricilerin DSO'lara da hizmet vereceği mekanizmalar (Entegre Esneklik Piyasa Modeli) için gerekli mevzuat düzenlemeleri kaçınılmaz olacaktır. Zira, dağıtık jeneratörler, elektrikli araçlar ve depolama sistemlerinin dağıtım sistemlerine entegrasyonu ile yakın bir gelecekte dağıtım şebekelerinde esneklik ihtiyacı daha çok hissedilmeye başlayacak olup, bu ihtiyacın sağlanmasında talep birleştiricilerin kilit rol üstlenmesi beklenmektedir.

Çalışmada gerçekleştirilen bilgisayar simülasyon analizlerinde de gösterildiği üzere, talep birleştiricilerinden sağlanabilecek şebeke esneklik çözümleri sayesinde, şebekede çok kısa süreli meydana gelen teknik kısıtlar (aşırı yüklenme veya aşırı gerilim düşümü / yükselmesi gibi) nedeniyle şebekede yapılacak aşırı kapasite yatırımlarının önüne geçilebilecektir. Ayrıca, elektrik piyasalarında yaşanabilecek darboğazlarda piyasa fiyatlarının yükselmesinin önlenmesinde önemli bir katkı sağlanabilecektir. Diğer yandan, talep yönetimi suretiyle şebekenin esnekliğinin artacak olması, yenilenebilir enerji kaynaklarının elektrik üretimindeki payının güvenli bir şekilde artmasına yol açacaktır. Enerji sektöründe yenilenebilir enerji üretim payının artması karbon emsiyonlarının azaltılmasında kritik bir öneme sahiptir. Paris Antlaşmasına imza atan ülkelerin karbon emisyonlarını sınırlama hedeflerini gerçekleştirmesi sonrası, karbon emisyonlarını sınırlayamayan ülkelere ek vergi gibi bazı yaptırımlar uygulaması kaçınılmaz görünmektedir. Dolayısıyla, talep yönetimi mekanizmalarının sosyoekonomik açıdan kaçınılmaz bir ihtiyaç olduğu anlaşılmaktadır. 
Tör, O.B. \& H. Oğuz \& S.M. Kısakürek \& E.N. Kurşuncu \& A.O. Köksal (2021), "Talep Birleştiricilerin Rol Aldığı Elektrik Piyasa Mekanizmaları ve Türkiye'deki Mevcut Durum Analizi”, Sosyoekonomi, 29(49), 307-322.

\section{Kaynaklar}

Eid, C. \& P. Codani \& Y. Chen \& Y. Perez \& R. Hakvoort (2015), “Aggregation of demand side flexibility in a smart grid: A review for European market design", IEEE 12th International Conference on the European Energy Market (EEM), 1-5.

ENTSO-E (2014), Network Code on Electricity Balancing (EB), <https://docstore.entsoe.eu/Documents/Network\%20codes\%20documents/NC\%20EB/14 0806_NCEB_Resubmission_to_ACER_v.03.PDF>, 11.11.2019.

ENTSO-E (2015), Towards Smarter Grids: Developing TSO and DSO Roles and Interactions for the Benefit of Consumers, <https://docstore.entsoe.eu/Documents/Publications/Positio n\%20papers\%20and\%20reports/150303_ENTSO-E_Position_Paper_TSODSO_interaction.pdf>, 11.11.2019.

EPDK (2019), 6446 Sayılı Elektrik Piyasası Kanunu, <https://www.epdk.org.tr/Detay/Icerik/3-0-02256/kanunlar>, 19.11.2019.

European Commission (2019), Clean energy for all Europeans package, <https://ec.europa.eu/energy/en/topics/energy-strategy-and-energy-union/clean-energyall-europeans $>, 25.11 .2019$.

Kocaarslan, İ. \& H. Tiryaki (2015), "Yük Dağıtım Sistemlerinde Karışık Tamsayı Programlama Algoritmas1 ile Optimizasyon", International Journal of Engineering Research and Development, 7(1), 2-11.

Koltsaklis, N.E. \& A.S. Dagoumas \& I.P. Panapakidis (2017), "Impact of the penetration of renewables on flexibility needs", Energy Policy, 109, 360-369.

Merino, J. \& I. Gómez \& E. Turienzo \& C. Madina (2016), “Ancillary service provision by RES and DSM connected at distribution level in the future power system", SmartNet Project, D1(1).

Ochoa, L.N. \& F. Pilo \& A. Keane \& P. Cuffe \& G. Pisano (2016), “Ancillary Service Provision by RES and DSM posture: ensuring that future European distribution networks are ready for more active roles", IEEE Power and Energy Magazine, 14(5), 16-28.

Olivella-Rosell, P., et al. (2018), "Local flexibility market design for aggregators providing multiple flexibility services at distribution network level", Energies, 11(4), 822-840.

Sanli, B. \& M. Alanyali (2014), Türkiye Elektrik Piyasasında Talep Katılımının Tasarımı, 2019, <http://www.barissanli.com/calismalar/2013/bsanli-malanyali-talepyonetimiaralik2013.pdf>, 19.11.2019.

SEDC (2017), Explicit Demand Response in Europe Mapping the Markets, <http://www.smarten.eu/wp-content/uploads/2017/04/SEDC-Explicit-DemandResponse-in-Europe-Mapping-the-Markets-2017.pdf>, 19.11.2019.

Smart Energy Europe (2019), <http://www.smarten.eu>, 19.11.2019. 